\title{
Spectral studies on inclusion complexation between 3-hydroxyflavone and 2-Hydroxypropyl- $\beta$-cyclodextrin
}

\author{
Arumugam Praveena ${ }^{1}$, Samikannu Prabu $^{3}$, Rajamohan Rajaram ${ }^{2 *}$, \\ ${ }^{1}$ Department of Chemistry, Idhaya Engineering College for Women, ChinnaSalem. 606 201, TN, India \\ ${ }^{2}$ Department of Chemistry, SKP Engineering College, Tiruvannamalai-606 611, TN, India \\ ${ }^{3}$ Department of Chemistry, IFET College of Engineering, Villupuram-605 108, TN, India
}

\begin{abstract}
3-hydroxy-2-phenylchromen-4-one (HF) is a flavonols that is formed when hypoxanthine is attached to a ribose ring (also known as a ribofuranose) via a $\beta$ - $\mathrm{N}_{9}$-glycosidic bond. Cyclodextrins are able to form host-guest complexes with hydrophobic molecules given the unique nature imparted by their structure.As a result, these molecules have found a number of applications in a wide range of fields. The inclusion complex of HF with $2 \mathrm{HP}-\beta-\mathrm{CD}$ is prepared by various synthetic method such as physical method (PM), kneading method (KM) and co-precipitation method (CP). The solid inclusion complex is characterized by UV, luminescence spectra, Fourier transform infrared (FT-IR) spectroscopy, scanning electron microscopy (SEM) and powder X-ray diffraction (XRD). The anticancer activity of the solid complex is performed against breast cancer cell line and it is noticed that there is no much better activity than the HF alone. Both the HF and its solid complex showed the poor anticancer activity against MDA MB 231 cell line.
\end{abstract}

Keywords: 3-Hydroxyflavone; 2-Hydroxypropyl- $\beta$-Cyclodextrin; Inclusion Complex; XRD; Cytotoxicity

\section{Introduction}

3-Hydroxyflavone is a chemical compound. It is the backbone of all flavonols, a type of flavonoid. It is a synthetic compound, which is not found naturally in plants. It serves as a model molecule as it possesses an excited-state intramolecular proton transfer (ESIPT) effect $^{[1]}$ to serve as a fluorescent probe to study membranes for example ${ }^{[2]}$ or intermembrane proteins ${ }^{[3]}$. Although 3-hydroxyflavone is almost insoluble in water, its aqueous solubility (hence bio-availability) can be increased by encapsulation in cyclodextrin cavities $^{[4]}$. Recently some of the research work is carried out in HF by some other authors. Complex formation of HF in $\gamma$-CD medium and their excited state proton transfer (ESPT).

Cyclodextrins (CDx) are cyclic oligosaccharides formed from D-glucose units that provide a relatively hydrophobic binding site for guest molecules. The most common CDx have six $(\alpha)$, seven $(\beta)$, or eight $(\gamma)$ glucose units for which the internal cavity diameter

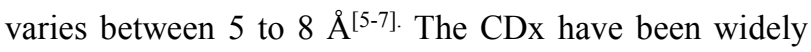
employed as host molecules in supramolecular chemistry, since the size of their cavities can be systematically varied and the hydroxyl groups at both rims can be derivatized $^{[8]}$. In addition, CDx are chiral, and this property has been explored for separation technology ${ }^{[9]}$ and in the study of the complexation of various guests. Guest molecules can interact with different regions of the $\mathrm{CDx}$, and different inclusion modes have been observed, e.g., inclusion within the cavity or binding to the rim. Cartoon representations frequently show an inclusion mode where the guest is located deeply within the CDx cavity, a perception that probably arises from the fact that the cavity is relatively hydrophobic. The inclusion complexation of guest molecules by the host cyclodextrins (CDs) and chemically modified cyclodextrins has been extensively studied in recent years as models of biological receptor-substrate

Copyright (C) 2018 Arumugam Praveena et al.

doi: 10.24294/jacs.v1i3.980

EnPress Publisher LLC.This work is licensed under the Creative Commons Attribution-NonCommercial 4.0 International License (CC BY-NC 4.0).

http://creativecommons.org/licenses/ by/4.0/ 
interactions and is currently a significant topic in chemistry and biochemistry ${ }^{[10-13]}$.

2-Hydroxypropyl - $\beta$-cyclodextrin (2HP- $\beta$-CD) represents a very useful alternative to the Beta Cyclodextrin molecules with much lower toxicities and improved solubility compared to the pristine molecules which qualify them to take a leading position in pharmaceutical and food industries. All hosts have been used in pharmaceutical formulations to the availability of the active ingredients and enhance the solubility ${ }^{[14-20]}$. Moreover, these molecules were found to play a crucial role in enhancing the shelf life of many compounds by acting as a molecular capsule where the bioactive species is protected from the harsh environmental factors around them such as light, $\mathrm{pH}$ and temperature ${ }^{[21-23]}$. Encapsulation of antioxidants, fragrance, flavonols and other food additives into cyclodextrins to enhance the solubility and non-volatility have also attracted lots of interest $^{[24-28]}$.

The supramolecular chemistry gives a broad idea of intermolecular interactions has been performed by host-guest system. The cyclodextrin is mostly hopeful to form inclusion complexes, especially with various guest molecules with proper structure ${ }^{[29]}$. In supramolecular chemistry, host-guest chemistry describes complexes that are composed of two or more molecules or ions that are held together in unique structural relationships by forces other than those of full covalent bonds. Host-guest chemistry encompasses the idea of molecular recognition and interactions through non covalent bonding.

Globally breast cancer is the most frequent female malignancy. It is the most frequently diagnosed cancer and is the second leading cause of cancer death among women in India. Despite advances in cancer treatment over the past decades, the prognosis of patients with breast cancer breast cancer has improved only to a small extent. Thus, there is an urgent need to develop new and effective strategies for the prevention and treatment of this form of cancer. Breast cancer is when cancer develops from breast tissue. Signs of breast cancer may include a lump in the breast, a change in breast shape, dimpling of the skin, fluid coming from the nipple, or a red scaly patch of skin. In those with distant spread of the disease, there may be bone pain, swollen lymph nodes, shortness of breath, or yellow skin.

In our earlier results are focused the study of complexation of some organic compounds with $\beta-C D$ based on proton shift effect ${ }^{[30-32]}$. Our aim of the present work is to evaluate the effect of inclusion complexation of HF with 2-HydroxyPropyl $-\beta$-Cyclodextrin in solid state. About solid inclusion complex, common used methods include UV, Fluorescence spectra, FT-IR, Powder X-ray diffraction. Many inclusion complexes of guests with CDs were studied by these methods ${ }^{[33-34]}$. In this work, we not only studied the character of HF-2HP- $\beta$-CD complex, we tried the anticancer effect of pure $\mathrm{HF}$ and their solid complexes against MDA MB 231 cell line.

\section{Materials \& methods}

\subsection{Materials}

Hydroxy flavone (HF) and2-HydroxyPropyl $-\beta$-Cyclodextrin (2HP- $\beta$-CD) are purchased from Alfa Acer and used as received. Distilled water is used throughout the study. 3-(4,5-dimethyl thiazol-2-yl)-5-diphenyl tetrazolium bromide (MTT), Fetal Bovine serum (FBS), Phosphate Buffered Saline (PBS), Dulbecco's Modified Eagle's Medium (DMEM) and Trypsin are obtained from Sigma Aldrich Co, St Louis, USA. EDTA, Glucose and antibiotics from Hi-Media Laboratories Ltd., Mumbai. Dimethyl Sulfoxide (DMSO) and Propanol from E.Merck Ltd., Mumbai, India.

\subsection{Cell lines and Culture medium}

MDA MB 231 (Breast carcinoma) cell line is procured from National Centre for Cell Sciences (NCCS), Pune, India. Stock cells are cultured in DMEM supplemented with $10 \%$ inactivated Fetal Bovine Serum (FBS), penicillin (100 IU/ml), streptomycin $(100 \mu \mathrm{g} / \mathrm{ml})$ and amphotericin B $(5 \mu \mathrm{g} / \mathrm{ml})$ in an humidified atmosphere of $5 \% \mathrm{CO}_{2}$ at $37^{\circ} \mathrm{C}$ until confluent. The cells are dissociated with TPVG solution $(0.2 \%$ trypsin, $0.02 \%$ EDTA, $0.05 \%$ glucose in PBS). The stock cultures are grown in $25 \mathrm{~cm}^{2}$ culture flasks and all experiments are carried out in 96 microtitre plates (Tarsons India Pvt. Ltd., Kolkata, India).

\subsection{Preparation of solid inclusion complexes}

The solid inclusion complexes of $\mathrm{HF}$ and $2 \mathrm{HP}-\beta-\mathrm{CD}$ were prepared using physical mixture, kneading method and co-precipitation techniques.

\subsubsection{Preparation of physical mixture of the}




\section{HF and HCD}

In the physical mixture process, the accurate weight of $\mathrm{HF}$ and $2 \mathrm{HP}-\beta-\mathrm{CD}$ are allowed to continuous agitation using a mortar and pestle for $10 \mathrm{~min}$. Finally we obtained the homogeneous mixture of $\mathrm{HF}$ and $2 \mathrm{HP}-\beta-\mathrm{CD}$ called physical mixture (PM)

\subsubsection{Preparation of solid complex by kneading method}

The pure HF and 2HP- $\beta-C D$ substances are accurately weighed and transferred into a pestle and mortar. Then, sufficient quantity of water is added in it to make a pasty form. The whole content is further allowed for grinding up to half an hour with pestle in mortar itself under careful condition. A yellow powder is obtained as called kneading product after it is dried for 48 hours in an oven at $303 \mathrm{~K}$.

\subsubsection{Preparation of the HF and $\beta-\mathrm{CD}$ by co- precipitation method}

The inclusion complex of $\mathrm{HF}$ and $2 \mathrm{HP}-\beta-\mathrm{CD}$ is prepared using the co-precipitation method. The accurate weight of $2 \mathrm{HP}-\beta-\mathrm{CD}$ is dissolved in distilled water to become a saturated solution. Other hand accurate weight of of HF is dissolved in distilled water to get a saturated solution. The HF solution is added slowly to the $2 \mathrm{HP}-\beta-\mathrm{CD}$ solution up to suspension is formed. The suspension is stirred continuously for 48 hours at $303 \mathrm{~K}$. The solution is kept in a refrigerator for 24 hours. After 24 hours, the solution became as yellow precipitate called as solid complex of HF with $2 \mathrm{HP}-\beta-\mathrm{CD}$.

\subsection{Preparation of Test Solutions for cytotoxic study}

For Cytotoxicity studies, each weighed test drugs are separately dissolved in distilled DMSO and volume is made up with DMEM supplemented with $2 \%$ inactivated FBS to obtain a stock solution of $1 \mathrm{mg} / \mathrm{ml}$ concentration and sterilized by filtration. Serial two fold dilutions are prepared from this for carrying out cytotoxic studies.

\subsection{Instruments}

UV-Visible spectra are recorded with UV-1800 SHIMADZU spectrophotometer while luminescence spectra are recorded between the wavelength ranges from 270 to $800 \mathrm{~nm}$ with RF-5301PC Spectrofluorophotometer. FT-IR spectra are obtained with iD1 Thermo nicolate iS5 FT-IR spectrophotometer using $\mathrm{KBr}$ pellet. The range of spectra is from $500-4000 \mathrm{~cm}^{-1}$. Microscopic morphological structure measurements are performed with FEI Quanta FEG 200 scanning electron microscope (SEM). Powder $\mathrm{X}$-ray diffraction spectra are taken by $\mathrm{D} 8$ Advance X-ray instrument (BRUKER, Germany) with $2.2 \mathrm{KW} \mathrm{Cu}$ anode, ceramic $\mathrm{X}$ - ray tube as the source, Lynx Eye (Silicon strip detector technology) as the detector, Ni filter as the Beta filter and zero back ground sample holder, PMMA sample holder. TG/DTA analysis is carried out with TGA 4000 perkin elmer in nitrogen atmosphere at $20 \mathrm{ml} / \mathrm{min}$. The temperature range is $35-600 \mathrm{deg}$ with heating rate 10 $\mathrm{deg} / \mathrm{min}$.

\section{Results \& discussion}

\subsection{Analysis of inclusion complex by UV Spectra}

The UV spectra of pure HF, PM, KM and solid complex (CP) are displayed in Figure $\mathbf{1}$ and their respective data are given in Table 1 The pure HF gives the maximum at $440.0 \mathrm{~nm}$ with absorbance 0.075 . For $\mathrm{PM}$ and $\mathrm{KM}$ products, the maximum is observed at 442.0 and $443.5 \mathrm{~nm}$ with the absorbance 0.098 and 0.123 , respectively. Whereas for the solid complex (CP) the absorption maximum is observed at $449.5 \mathrm{~nm}$. Here we noticed that, the change in absorption maxima for the PM and KM products while compare with pure HF. This small change in maximum is due to the presence of 2 HP- $\beta$-CDin it. On the other hand, red shifted maximum is observed $(9.5 \mathrm{~nm})$ with significance enhancement in absorbance for solid complex when comparing with pure HF, PM and KM. This change further supports the formation of inclusion complex between $\mathrm{HF}$ and 2HP- $\beta$-CD.

\begin{tabular}{|l|l|l|l|l|}
\hline \multirow{2}{*}{ Compound } & \multicolumn{2}{l|}{ UV } & \multicolumn{2}{l|}{ Luminescence } \\
\cline { 2 - 5 } & $\lambda_{\max }$ & Abs & $\lambda_{\text {emi }}$ & Intensity \\
\hline Pure- HF & 440.0 & 0.075 & 560.0 & 40.0 \\
\hline PM- HF & 442.0 & 0.081 & 560.5 & 100.0 \\
\hline KM-HF & 443.5 & 0.095 & 563.0 & 155.3 \\
\hline CP-HF & 449.5 & 0.123 & 568.5 & 285.0 \\
\hline
\end{tabular}

Table 1. UV and Luminescence spectral maxima of HF with B-CD 


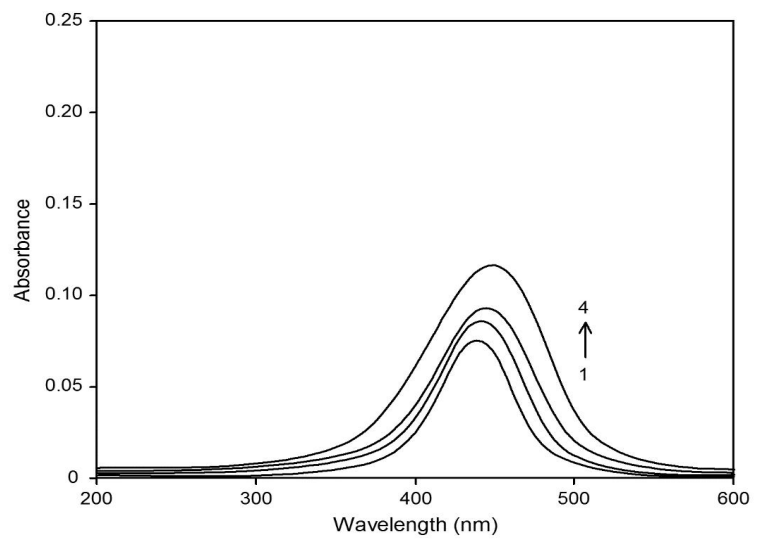

Figure 1; UV Spectra of 1) Pure HF, 2) PM, 3) KM and 4) CP product of HF: $2 \mathrm{HP}-\beta-\mathrm{CD}$.

\subsection{Analysis of inclusion complex by luminescence spectra}

Figure 2 depicts the luminescence spectra of pure HF, PM, KM and solid complex (CP) and the respective data are given in Table 1. HF showed that the emission maximum at $560.0 \mathrm{~nm}$ with fluorescence intensity 40.0 . The emission maxima are observed at 560.5 and $563 \mathrm{~nm}$ with the intensity 100 and 155.3 for PM and KM products, respectively. The $\lambda_{\text {emi }}$ at $568.5 \mathrm{~nm}$ is with intensity 285.0 is observed for solid complex. No much change is observed in emission maximum and its intensity for the $\mathrm{PM}$ and $\mathrm{KM}$ products and these are more resemblance with the fluorescence spectra of pure HF. This small change in maximum and its respective intensity is due to the presence of $2 \mathrm{HP}-\beta-\mathrm{CD}$ role in it. On the other hand, red shifted maximum is observed (around $8.5 \mathrm{~nm}$ ) with significant enhancement in their intensity for solid complex (CP product) when comparing it with pure HF, PM and KM. This remarkable change is attributed to the formation of inclusion complex between HF and $2 \mathrm{HP}-\beta-\mathrm{CD}$.

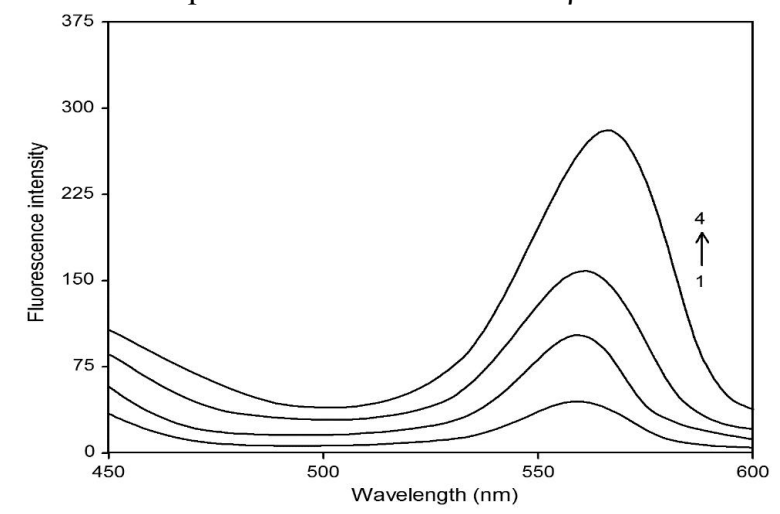

Figure 2. Fluorescence spectra of 1) Pure HF,2) PM, 3) $\mathrm{KM}$ and 4) CP product of HF: $2 \mathrm{HP}-\beta-\mathrm{CD}\left(\lambda_{\mathrm{exc}}=440.0 \mathrm{~nm}\right)$

\subsection{FT-IR Study}

The IR spectra of the compounds HF, 2HP- $\beta-C D$, PM, KM, CP products are shown in Figure 3. The formation of complex is confirmed by the comparison of pure reactants (HF and 2HP- $\beta-C D$ ) with its inclusion complexed products. The IR spectrum of pure $\mathrm{HF}$ showed their $-\mathrm{OH}, \mathrm{C}=\mathrm{O}, \mathrm{C}=\mathrm{C}, \mathrm{C}-\mathrm{O}-\mathrm{C}$ stretching frequencies at $3469.64,1608.75,1559.01$ and 1280.0 $\mathrm{cm}^{-1}$ (Table 2). Comparing the three products the PM method product showed very broad and less intense peaks $\left(3228.27,1607.93,1559.45\right.$ and $\left.1077.61 \mathrm{~cm}^{-1}\right)$ for the functional groups $-\mathrm{OH}, \mathrm{C}=\mathrm{O}, \mathrm{C}=\mathrm{C}, \mathrm{C}-\mathrm{O}-\mathrm{C}$, respectively. By comparing the $\mathrm{PM}$ and $\mathrm{KM}$ products, stretching frequencies are observed slightly sharp and intense peaks at 3410.29, 1608.87, 1561.67 and 1086.87 $\mathrm{cm}^{-1}$. Interestingly, the $\mathrm{CP}$ product forms an inclusion complex which is confirmed by its strong, sharp and intense stretching frequencies observed at $3202.34(-\mathrm{OH})$, $1664.25(\mathrm{C}=\mathrm{O}), 1575.74(\mathrm{C}=\mathrm{C})$ and $1030.7(\mathrm{C}-\mathrm{O}-\mathrm{C})$, respectively. Eventually, among the three methods (PM, $\mathrm{KM}$ and $\mathrm{CP}$ ), the $\mathrm{CP}$ product only form the stable inclusion complex than the PM and KM products.

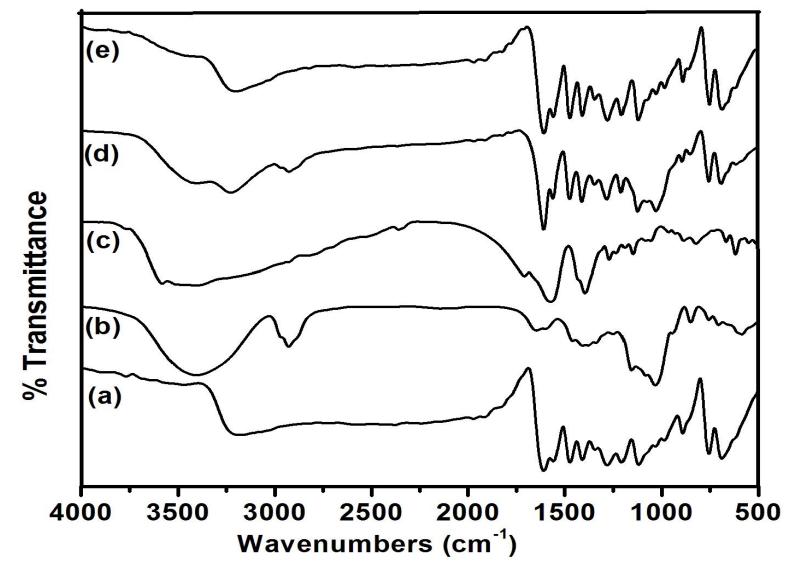

Figure 3; FT-IR spectra of a) HF, b) 2HP- $\beta-C D$, c) PM, d) $\mathrm{KM}$ and e) CP products. 


\begin{tabular}{|c|c|c|c|c|}
\hline $\begin{array}{l}\text { Stretching } \\
\text { Frequencies }\end{array}$ & Pure HF & $\begin{array}{l}\text { PM } \\
\text { Produ } \\
\text { cts }\end{array}$ & $\begin{array}{l}\text { KM } \\
\text { Produ } \\
\text { cts }\end{array}$ & $\begin{array}{l}\text { CP } \\
\text { Prod } \\
\text { ucts }\end{array}$ \\
\hline$-\mathrm{OH}$ & 3469.64 & $\begin{array}{l}3228.2 \\
7\end{array}$ & $\begin{array}{l}3410.2 \\
9\end{array}$ & $\begin{array}{l}3202 . \\
34\end{array}$ \\
\hline $\mathrm{C}=\mathrm{O}$ & 1608.75 & $\begin{array}{l}1607.9 \\
3\end{array}$ & $\begin{array}{l}1608.8 \\
7\end{array}$ & $\begin{array}{l}1664 . \\
25\end{array}$ \\
\hline $\mathrm{C}=\mathrm{C}$ & 1559.01 & $\begin{array}{l}1559.4 \\
5\end{array}$ & $\begin{array}{l}1561.6 \\
7\end{array}$ & $\begin{array}{l}1575 . \\
74\end{array}$ \\
\hline $\mathrm{C}-\mathrm{O}-\mathrm{C}$ & 1280.00 & $\begin{array}{l}1077.6 \\
1\end{array}$ & $\begin{array}{l}1086.8 \\
7\end{array}$ & $\begin{array}{l}1030 . \\
17\end{array}$ \\
\hline
\end{tabular}

Table 2. FT-IR frequencies for various stretching in HF and their solid complexes

\subsection{SEM image analysis}

Scanning electron microscopy (SEM) is a qualitative method used to study the structural aspects of raw materials, i.e., CDs and guest or the products obtained by different methods of preparation, such as physical method, kneading method and Co-Precipitation method. The SEM photographs of $2 \mathrm{HP}-\beta-\mathrm{CD}, \mathrm{HF}$, its inclusion complexes are shown in Figure 4. Pure HF showed that the clear rock and needle structure

(Figures $4 \mathrm{a}$ and $4 \mathrm{~b}$ ) and $2 \mathrm{HP}-\beta-\mathrm{CD}$ crystallized as a spherical crystal with cavity structures. The PM and KM product of HF: $2 \mathrm{HP}-\beta-\mathrm{CD}$ revealed some similarities with the crystals of the free molecules and showed both crystalline components (Figures $4 \mathrm{c}$ and $4 \mathrm{~d} \&$ Figures $4 \mathrm{e}$ and $4 \mathrm{f})$. In contrast, the HF: $2 \mathrm{HP}-\beta-\mathrm{CD}$ displayed in the form of compact and homogeneous plate-like structures with crystal particles in which the original morphology of both components disappeared (Figures $4 \mathrm{~g}$ and $4 \mathrm{~h}$ ). The shape and sizes of HF and $2 \mathrm{HP}-\beta-\mathrm{CD}$ particles are different from those of the inclusion complex, which may indicate inclusion complexation from the processing of HF and $2 \mathrm{HP}-\beta-\mathrm{CD}$ by co-precipitation method which indicates strong indication of inclusion complex formation by CP method.
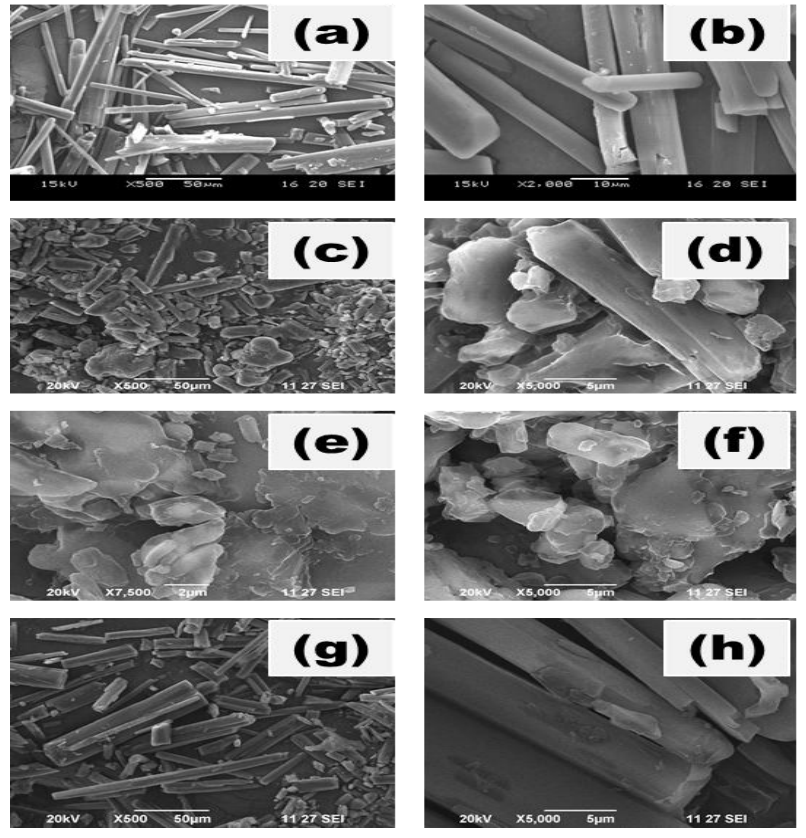

Figure 4; SEM photographs of a) HF (x500), b) HF (x2000) c) PM (x500),d) PM (x5000), e) KM (x7500), f) KM (x5000), g) CP product (x500) and h) CP product (x5000).

\subsection{Powder XRD Study}

The XRD patterns of pure HF, $2 \mathrm{HP}-\beta-\mathrm{CD}$, inclusion complexes obtained by PM, KM and CP methods are depicted in Figure 5. The characteristic diffraction peaks of HF are observed at $2 \theta 11.59,16.15,18.24,25.87$ and $32.86^{\circ}$ for assuming it is in crystalline nature.

The diffraction peaks of solid complex of HF with $2 \mathrm{HP}-\beta-\mathrm{CD}$ showed peaks at $2 \theta 10.88,11.44,12.36$, $15.12,16.28,18.24,21.5,24.56$ and $27.76^{\circ}$. The more intense peaks of pure HF at $2 \theta 11.59,16.15,18.24,25.87$, and $32.86^{\circ}$ are reduced and some of the peaks are disappeared significantly in solid inclusion complex by CP method.

This showed that the crystalline nature is reduced gradually and increases amorphous nature. The formation of amorphous nature complex confirmed the stable complex is obtained between HF and 2HP- $\beta-C D$. In addition, the presence of new intense peak showed the changes in HF: $2 \mathrm{HP}-\beta-\mathrm{CD}$ environment after inclusion complex formation. 


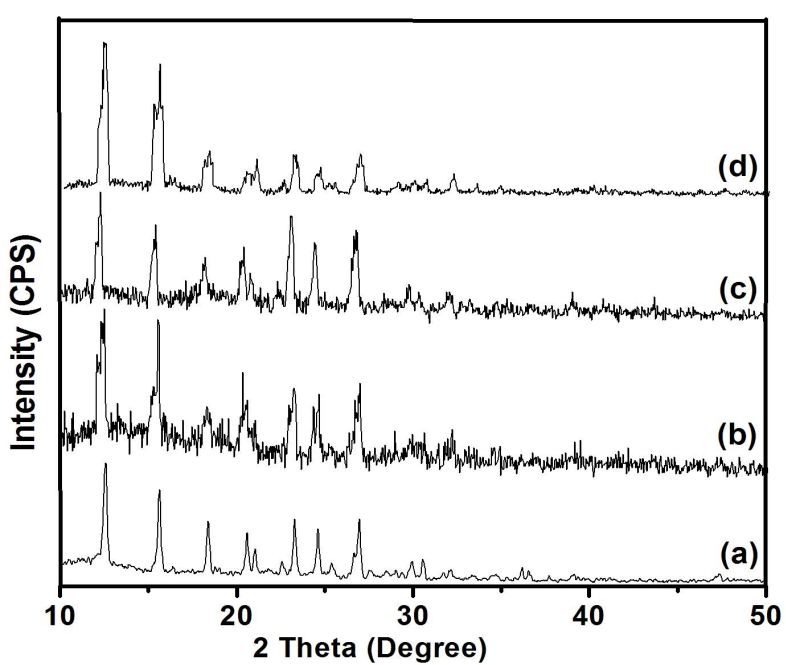

Figure 5. Powder XRD patterns of a) HF, b) PM, c) KM and d) CP Product

\subsection{TG/DTA analysis of solid complex}

Figure 6 showed the TG/DTA curves for pure HF, $\mathrm{PM}, \mathrm{KM}$ and $\mathrm{CP}$ products. The TG/DTA analysis of pure $2 \mathrm{HP}-\beta-\mathrm{CD}$ showed only one endothermic peak at $355^{\circ} \mathrm{C}$ whereas the pure $\mathrm{HF}$ showed an endothermic peak at $268.9^{\circ} \mathrm{C}$ which is assigned to the melting point of the corresponding compounds respectively. For PM and KM method, the same endothermic peak is observed at $251^{\circ} \mathrm{C}$ and $260^{\circ} \mathrm{C}$ respectively whereas in $\mathrm{CP}$ method it is observed at $275^{\circ} \mathrm{C}$. Based on the TG/DTA analysis of PM and $\mathrm{KM}$ products, there is a small interaction obtained in between HF and 2HP- $\beta-C D$. But, there is a strong interaction obtained in $\mathrm{CP}$ method product. Eventually, the TG/DTA analysis confirmed the formation of inclusion complex.
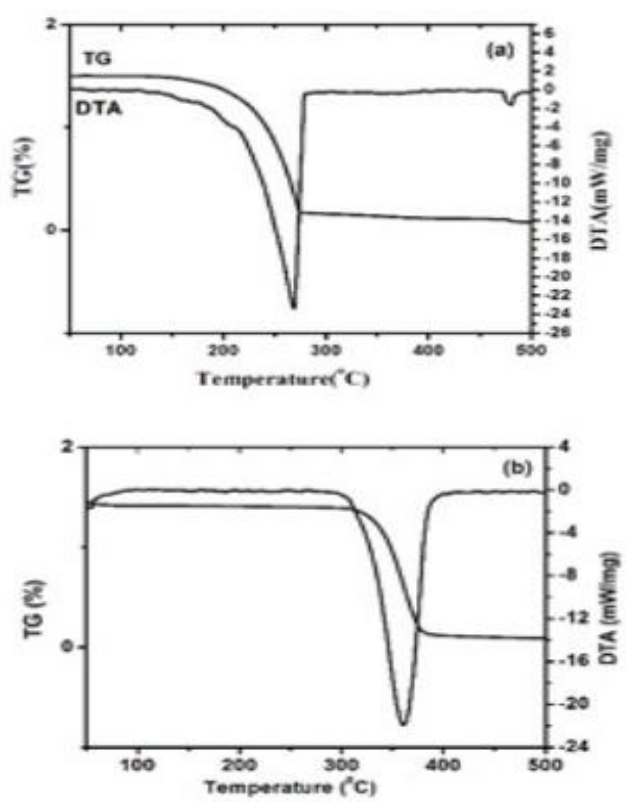
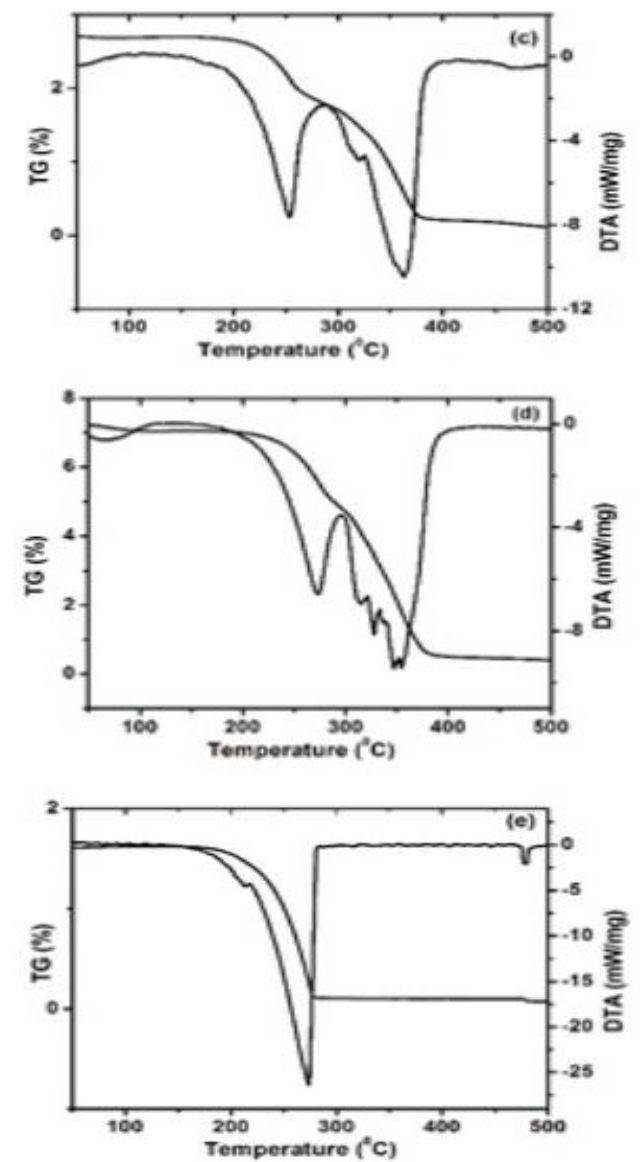

Figure 6; TG/DTA of a) HF, b) $2 \mathrm{HP}-\beta-\mathrm{CD}$ c) PM, d) KM and e) CP Products.

\subsection{FT Raman Analysis}

FT-Raman spectra of pure $\mathrm{HF}$ and $\mathrm{CP}$ products are depicted in Figure 7. The stretching frequency observed at $3477.24 \mathrm{~cm}^{-1}$ is responsible for the $-\mathrm{OH}$ group of pure HF whereas the frequency for this stretching is completely disappeared for the $\mathrm{CP}$ product.

The C-H group shows a frequency at $3153.17 \mathrm{~cm}^{-1}$ and $3072.45 \mathrm{~cm}^{-1}$ likely to be for the $\mathrm{CP}$ product (Table 3). Peaks observed at $2380.95 \mathrm{~cm}^{-1}$ and $1970.73 \mathrm{~cm}^{-1}$ meant for $\mathrm{C}=\mathrm{C}$ group and observed the absence in $\mathrm{CP}$. The $\mathrm{C}=\mathrm{O}$ group appeared at $1611.8 \mathrm{~cm}^{-1}$ and for $\mathrm{CP}$ is observed at $616.92 \mathrm{~cm}^{-1}$. The major changes are observed in $-\mathrm{OH}$, aromatic $\mathrm{C}-\mathrm{H},-\mathrm{C}=\mathrm{O}$ frequencies for CP Products. The other stretching frequencies such as $\mathrm{C}=\mathrm{C}$, and etc., are also changed while interacting with 2 HP- $\beta$-CD. The FT-IR spectra are more resembled with FT-Raman spectra. No much difference between FT-Raman and FT-IR in analyzing the HF and its solid complex. Both the spectral analysis seems to the same conclusion. Hence, the part of the HF molecule has been included into the $2 \mathrm{HP}-\beta-\mathrm{CD}$ cavity. 

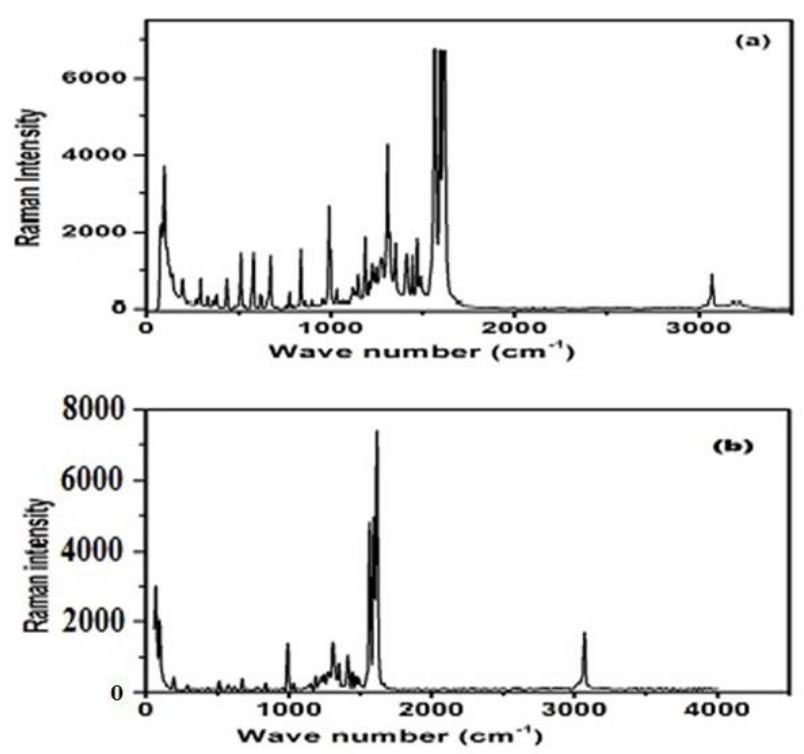

Figure 7; FT-Raman Spectra of a) Pure HF and b) CPproduct with 2HP- $\beta$-CD.

\begin{tabular}{|c|c|c|}
\hline Pure HF $\left(\mathrm{cm}^{-1}\right)$ & $\begin{array}{l}\text { CP product } \\
\left(\mathrm{cm}^{-1}\right)\end{array}$ & Group Frequency \\
\hline 3477.24 & - & $\begin{array}{l}-\mathrm{OH} \text { stretching } \\
\text { frequency }\end{array}$ \\
\hline 3153.17 & 3072.45 & Aromatic C-H \\
\hline $\begin{array}{l}2380.95 \\
1970.73\end{array}$ & - & $\begin{array}{l}\mathrm{C}=\mathrm{C} \text { shoulders and } \\
\text { overtones }\end{array}$ \\
\hline 1611.85 & 1616.92 & $\mathrm{C}=\mathrm{O}$ \\
\hline 1562.30 & 1595.30 & $\begin{array}{lr}\mathrm{C}=\mathrm{C} & \text { Skeletal } \\
\text { vibration } & \text { of } \\
\text { aromatic } & \\
\end{array}$ \\
\hline $1471.24,1414.11$ & $1488.64,1412.64$ & $\begin{array}{l}\mathrm{C}-\mathrm{H} \\
\text { asymmetric bendin } \\
\text { g mode }\end{array}$ \\
\hline 1353.85 & 1350.47 & $\begin{array}{l}\mathrm{C}-\mathrm{H} \quad \text { in } \\
\text { plane bending } \\
\text { vibration }\end{array}$ \\
\hline $\begin{array}{l}1276.63, \\
1120.84,992.28\end{array}$ & $\begin{array}{l}\text { 1246.99, } \\
1032.64,992.21\end{array}$ & $\begin{array}{l}\mathrm{C}-\mathrm{O} \text { and } \mathrm{C}-\mathrm{O}-\mathrm{C} \\
\text { Stretching vibration }\end{array}$ \\
\hline 898.11 & 837.44 & $\begin{array}{l}\text { O-H Out of } \\
\text { plane bending } \\
\text { vibration }\end{array}$ \\
\hline 690.09 & 673.09 & $\begin{array}{l}\mathrm{C}-\mathrm{H} \text { out of } \\
\text { plane bending } \\
\text { vibration }\end{array}$ \\
\hline
\end{tabular}

Table 3. FT-Raman frequency data of $\mathrm{HF}$ and its $\mathrm{CP}$ products with $2 \mathrm{HP}-\beta-\mathrm{CD}$

\subsection{In-vitro cytotoxic effect of HF against MDA MB 231 cell line}

An in-vitro comparison of cytotoxicity of free HF, $2 \mathrm{HP}-\beta-\mathrm{CD}$ and inclusion complex are assessed to verify its safe application in pharmaceutical formulations. The cytotoxic effect of pure HF and their solid complex with $2 \mathrm{HP}-\beta-\mathrm{CD}$ are tested with MDA MB 231 cell line. Various concentrations of pure HF and their solid complex are prepared in the order of $62.5,125,250,500$ and $1000 \mu \mathrm{m} / \mathrm{ml}$ separately. For each concentration, the cytotoxic effect is tested. The percentage of inhibition and corresponding $\mathrm{CTC}_{50}$ value for each concentration is given in Table 4. By increasing the concentrations of HF, the percentage of inhibition is gradually increased (Figure 8). At a higher concentration of HF $(1000 \mathrm{mg} / \mathrm{ml})$ it gives $22.22 \%$ and $\mathrm{CTC}_{50}$ value exceeding 1000 . The solid complex of HF with $2 \mathrm{HP}-\beta-\mathrm{CD}$ is shown that the same kind of trend in percentage of inhibition (15.86\%) and $\mathrm{CTC}_{50}$ value is exceeded to 1000 . Both the substances (HF and solid complex) showed only a little effect against MDA MB 231 cell line (Figure 9). Since, the $\mathrm{CTC}_{50}$ should not exceed 1000; it's suitable for cytotoxic effect. Unfortunately, the $\mathrm{CTC}_{50}$ value is not in control and it exceeds 1000 . The cytotoxic effect of pure HF has not reached the level which we expected.

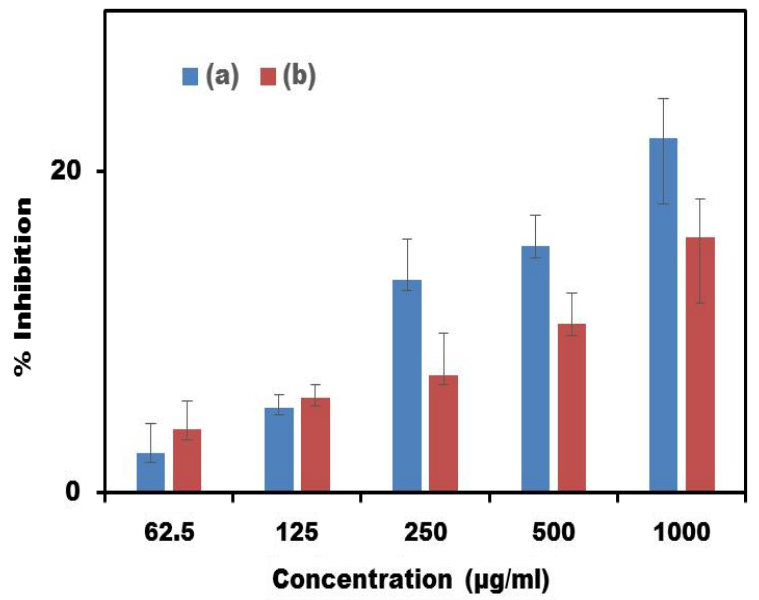

Figure 8; Cytotoxic effect of (a) HF and (b) their solid complex against MDA MB 231 Cell line. 


\begin{tabular}{|c|c|c|c|c|}
\hline SI. No & $\begin{array}{l}\text { Name of } \\
\text { the sample }\end{array}$ & $\begin{array}{l}\text { Concentr } \\
\text { ations } \\
(\mu \mathrm{g} / \mathrm{ml})\end{array}$ & $\begin{array}{l}\text { Percentage } \\
\text { of inhibition }\end{array}$ & $\begin{array}{l}\mathrm{CTC}_{50} \\
(\mu \mathrm{g} / \mathrm{ml})\end{array}$ \\
\hline 1 & Pure HF & $\begin{array}{l}1000 \\
500 \\
250 \\
125 \\
62.5\end{array}$ & $\begin{array}{l}22.08 \pm 2.4 \\
15.38 \pm 1.9 \\
13.21 \pm 2.6 \\
5.32 \pm 0.8 \\
2.51 \pm 1.8\end{array}$ & $>1000$ \\
\hline 2 & $\begin{array}{l}\text { HF: } \\
2 \mathrm{HP}-\beta-\mathrm{CD}\end{array}$ & $\begin{array}{l}1000 \\
500 \\
250 \\
125 \\
62.5\end{array}$ & $\begin{array}{l}15.86 \pm 4.1 \\
10.54 \pm 0.8 \\
7.33 \pm 0.6 \\
5.92 \pm 0.5 \\
3.92 \pm 0.6\end{array}$ & $>1000$ \\
\hline
\end{tabular}

Table 4. Cytotoxic effect of HF and its complex against MDA MB 231 cell line

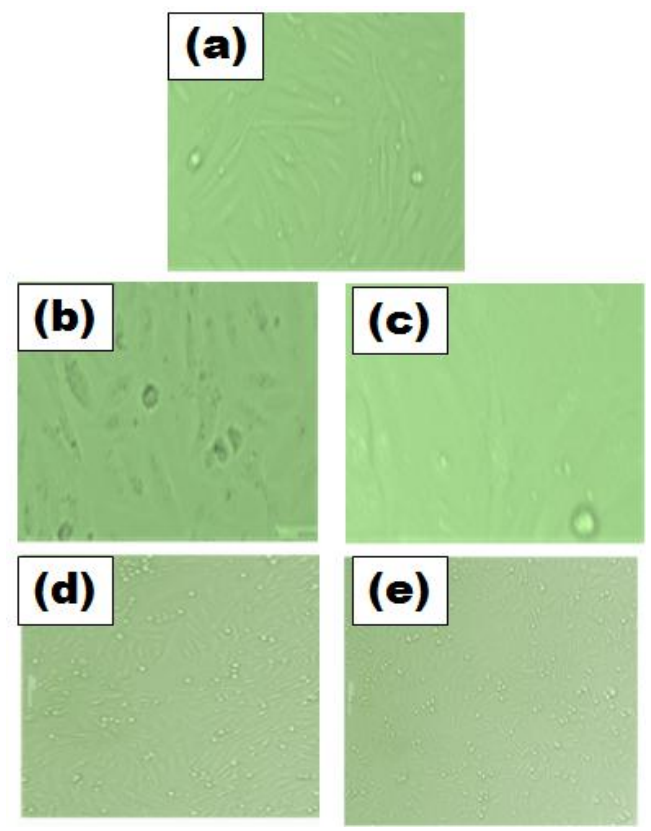

Figure 9; Photos of (a) MDA MB 231 Control, (b) HF Pure-1000C, (c) HF Pure -500C, (d) Inclusion Complex (HF: $2 \mathrm{HP}-\beta-\mathrm{CD})-1000 \mathrm{C}$, (e) Inclusion Complex (HF: $2 \mathrm{HP}-\beta-\mathrm{CD})$ $-500 \mathrm{C}$.

\section{Conclusions}

HF forms stable inclusion complex with 2HP- $\beta-C D$. Solid complex is verified by various analytical methods like UV and Fluorescence techniques. It showed that the remarkable changes in absorbance and fluorescence intensity with red shifted maximum. As the stretching frequencies of $\mathrm{HF}$ in aromatic $\mathrm{C}=\mathrm{C}$, aromatic $\mathrm{C}-\mathrm{H},-\mathrm{OH}$, $\mathrm{C}-\mathrm{O}-\mathrm{C}$ - and $\mathrm{C}=\mathrm{O}$ are significantly changed for those in solid complex. This part only entrapped in $\mathrm{CD}$ cavity. Hence no change in PM and KM. SEM and XRD analysis supports the formation of inclusion complex in solid state. HF and their complex showed that the poor anticancer activity against MDA MB 231 cell line. In addition, the toxicity profile of the inclusion complex (HF: 2HP- $\beta-C D)$ was also investigated. The inclusion complex of HF/ $2 \mathrm{HP}-\beta-\mathrm{CD}$ was found to be nontoxic against MDA MB 231 cells even at high concentration. The approach of making use of inclusion complexes may help in the design and development of HCD associated pharmaceutical formulations.

\section{References}

1. Wu Feng, Lin Lie, Li Xiang-Ping, et al. All-optical switchings of 3-hydroxyflavone in different solvents [J]. Chin. Phys. B, 17: 1461-1466.

2. Jayanti Guharay, Rupali Chaudhuri, Abhijit Chakrabarti, et al. Excited state proton transfer fluorescence of 3-hydroxyflavone in model membranes [J]. Spectrochim Acta Part A. 1997; 53 (3): 457-462.

3. Sudip Chaudhuri, Anwesha Banerjee, Kaushik Basu, et al. Interaction of flavonoids with red blood cell membrane lipids and proteins: Antioxidant and antihemolytic effects [J]. I.J.Biolog.Macromolec, 2007; 41 (1): 42-48.

4. Biswapathik Pahari, Sandipan Chakraborty, Pradeep K. Sengupta. Encapsulation of 3-hydroxyflavone in $\gamma$-cyclodextrin nanocavities: Excited state proton transfer fluorescence and molecular docking studies [J]. J.Molec.Struct, 2011; 1006 (1-3): 483-488.

5. Saenger W. Angew [J].Chem, Int. Ed. Engl. 1980; $19,344$.

6. Tabushi I, Acc Chem. Res. 1982; 15, 66.

7. Szejtli J, In Cyclodextrins, Szejtli J, et al. Elsevier Science Ltd.: New York, 1996; 3: 5.

8. Jicsinszky L, Fenyvesi E, Hashimoto $\mathrm{H}$, et al. Elsevier Science Ltd.: New York, 1996; 3: p 57.

9. Li S, Purdy, Chem WC. Rev. 1992; 92, 1457.

10. Eftink M R, Harrison JC, Bioorg Chem. 1981; 10: 388 .

11. Huroda Y, Hiroshige T, Takashi S, et al. Soc. 1989; 111: 1912.

12. Manka JS, Lawrence DSJ, Am. Chem. Soc. 1990; 112: 2441.

13. Harada A, Li J, Kamachi M. Nature, 1994; 370: 126.

14. MacEdo OFL, Andrade GRS, Conegero LS, et al. Physicochemical study and characterization of the trimethoprim/2- hydroxypropyl- $\gamma$-cyclodextrin inclusion complex [J]. Spectrochim. Acta Part A, 2012; 86: 101-106.

15. Misiuk W, Jasiuk E. Study of the inclusion 
interaction of HP- $\gamma$-cyclodextrin with bupropion and its analytical application [J]. J. Mol. Struct, 2014; 1060: 272-279.

16. Muankaew C, Jansook P, Sigurcrossed HH, et al. Cyclodextrin-based telmisartan ophthalmic suspension: Formulation development for water-insoluble drugs [J]. Int. J. Pharm, 2016; 507: 21-31.

17. Wei Y, Zhang J, Zhou Y, et al. Characterization of and enhanced bioactivity [J]. Carbohydr. Polym, 2017; 159: 152-160.

18. Prado AR, Yokaichiya F, Franco MKKD, et al. Complexation of oxethazaine with 2 -hydroxypropyl- $\beta$-cyclodextrin: increased drug solubility, decreased cytotoxicity and analgesia at inflamed tissues [J]. J. Pharm. Pharmacol, 2017; 69: 652-662.

19. Yan HH, Zhang JQ, Ren SH, et al. Experimental and computational studies of naringin/cyclodextrin inclusion complexation [J]. J. Incl. Phenom. Macrocycl. Chem, 2017; 88: 15-26.

20. Shityakov S, Salmas RE, Durdagi S, et al. Solubility profiles, hydration and desolvation of curcumin complexed with $\gamma$ - cyclodextrin and hydroxypropyl- $\gamma$-cyclodextrin [J]. J. Mol. Struct, 2017; 1134: 91-98.

21. do Carmo CS, Maia C, Poejo J, et al. Microencapsulation of $\alpha$-tocopherol with zein and $\beta$ - cyclodextrin using spray drying for colour stability and shelf-life improvement of fruit beverages [J]. RSC Adv, 2017; 7: 32065-32075.

22. Mangolima CS, Moriwakib C, Satoc F, et al. Curcumin- $\beta$-cyclodextrin inclusion complex: Stability, solubility, characterization by FT-IR, FT-Raman, X-ray diffraction and photoacoustic spectroscopy, and food application $[\mathrm{J}]$. Food Chem, 2014;153 (15): 361-370.

23. Wang X, Luo Z, Xiao Z. Preparation, characterization, and thermal stability of $\beta$ - cyclodextrin/soybean lecithin inclusion complex [J]. Carbohydr. Polym, 2014; 101: 1027-1032.

24. Wei Y, Zhang J, Memon AH, et al. Molecular model and in vitro antioxidant activity of a water-soluble and stable phloretin/hydroxypropyl- $\beta$ - cyclodextrin inclusion complex [J]. J. Mol. Liq, 2017; 236: 68-75.

25. Zhang CL, Liu JC, Yang WB, et al. Experimental and molecular docking investigations on the inclusion mechanism of the complex of phloridzin and hydroxypropyl- $\beta$-cyclodextrin [J]. Food Chem, 2017; 215: 124-128.

26. Cetin H, Ali B, Necla B, et al. Encapsulation of clove essential oil in

hydroxypropyl beta-cyclodextrin for characterization, controlled release, and antioxidant activity [J]. J Ournal Food Process Preserv, 2017: $1-8$.

27. Alonso ECP, Riccomini K, Silva LAD, et al. Development of carvedilol-cyclodextrin inclusion complexes using fluid-bed granulation: a novel solid-state complexation alternative with technological advantages [J]. J. Pharm. Pharmacol, 2016; 68: 1299-1309.

28. Li W, Liu X, Yang Q, et al. Preparation and characterization of inclusion complex of benzyl isothiocyanate extracted from papaya seed with $\beta$ cyclodextrin [J]. Food Chem, 2015; 184: 99-104.

29. Sambasevam KP, Mohamad S, Sarih NM, et al. Int. J. Mol. Sci, 2013; 14: 3671-3682.

30. Rajamohan R, Kothai Nayaki S, Swaminathan M, et al. 2011; 40: 803-817.

31. Rajamohan R, Kothai Nayaki S, Swaminathan M, et al. 2011; 21: 521-529.

32. Rajamohan R, Kothai Nayaki S, Swaminathan M. Spectrochim Acta Part A, 2008; 69: 371-377.

33. Zornoza A, Mart'1n C, anchez MS', et al. 1998; 169: 239.

34. Mura P, Bettinetti GP, Manderioli A, et al. 1998; 166: 189. 